\title{
Economic Distress Arising From Covid-19 Shutdowns as a Factor in Development of Anxiety Symptoms among Undergraduate Students in Anambra State, Nigeria
}

\author{
UJU CHRISTIANA NWANNA, IFEANYI MATHEW AZUJI, ${ }^{*}$ and \\ ESTHER CHINYERE EJICHUKWU
}

Department of Guidance and Counselling, Nnamdi Azikiwe University, Awka, Nigeria.

\begin{abstract}
The purpose of this study is to examine economic distress arising from COVID-19 shutdowns as a factor in development of anxiety symptoms among undergraduate students in Anambra State, Nigeria. Five research questions guided the study. Correlational research design was used in carrying out the study. A multi-stage sampling procedure was employed in the selection of 1,900 participants for this study. The instruments for data collection are questionnaires titled; "Distressing Economic Survey Questionnaire (PESQ)" and "Beck Anxiety Inventory (BAI)". The reliability coefficients of the instruments were 0.93 for PESQ and 0.92 for BAI. Data was collected by sending the questionnaires along with the consent form appended to it through e-mails, WhatsApp and Telegram messengers to the contacts of the participants and analyzed using range of aggregate scores in answering the research questions 1-3., Pearson r. for research questions 4-5. The findings showed that the undergraduate students' living status and housing condition are low contributory factors in the development of anxiety symptoms in Anambra State. Based on the findings of the study, it was recommended among others that there is a serious need to have fully functional guidance counsellors in the university who are not combining counselling with teaching. These guidance counsellors in the school will help to explore varieties of ways of coping with the distressing economic conditions to reduce feelings of anxiety and possibly handling the anxiety before it becomes a source of problem to the students.
\end{abstract}

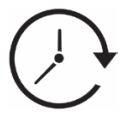

Article History

Received: 03 June 2020 Accepted: 15 September 2020

\section{Keywords}

Anxiety Symptoms;

Covid-19;

Coronavirus;

Counselling;

Economic Distress;

Housing Condition;

Living Status;

Shutdown.

\section{Introduction}

Economic issues could be a significant source of worry and anxiety for people, especially the students in the university whose main challenge usually has to do with finance and accommodation. An individual's challenge with finance may also

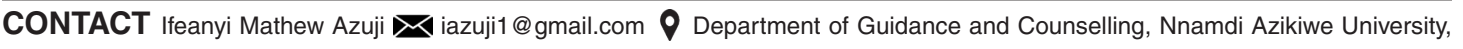
Awka, Nigeria

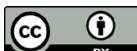

(C) 2020 The Author(s). Published by Enviro Research Publishers.

This is an $\partial$ Open Access article licensed under a Creative Commons license: Attribution 4.0 International (CC-BY).

Doi: http://dx.doi.org/10.12944/CRJSSH.3.2.11 
produce such overwhelmingly negative emotions and self-complaint that his or her mental and physical health may be adversely affected. Financial distress as a result of difficult economic issues could pose a challenge to the living status and accommodation for the students among others. It could also have negative effects on their relationships and family life.

Hence, economic challenges could come in various forms, and what one individual considers a burden or situation might not be a problem to another person in an unexpected situation. This basically could be attributed to the notion that individual economic disposition and income vary widely between people based on a number of contributory factors. An individual can control some of these factors; like housing accommodation, expenditure, living status, job, or career choice while some others may not.

The issue of COVID-19 economic shutdown for instance has ravaged many economies around the world and caused a noticeable imbalance in many countries, including Nigeria. According to the World Health Organisation (WHO, 2020), COVID-19 as recently discovered has its origin traced to a "new strain of coronavirus". Details about the symptoms, spread, and the threats posed are today being disseminated through various media channels and as people learn more on how the COVID-19 affect persons on daily basis and the spiralling death statistics across the globe, they tend to become even more anxious and panicky. More so, the fact that currently, there seems to be no available vaccine for COVID-19 makes the situation even worrisome.

The spate of coronavirus diseases according to WHO (2020) is today being described as "a Public Health Emergency of International Concern (PHEIC)" and the virus has continued to spread to many countries and territories, Nigeria is not left out. As the news continued to spread and more information is learned about the disease, governments all over the world have impressed on the general public to practice social distancing and the advice seems to culminate in mass government shutdowns and restrictions and self-isolation leading to a grinding halt in economic activities. With all the happenings and going by Nigeria's overwhelming dependency on oil receipts and recent releases by the National Bureau of Statistics (NBS, 2020), negative economic growth seems to have plunged the economy into a recession. Thus, one can assert that the aftermath of COVID-19 downturns has put the country in what could be perceived as serious economic distress.

Economic distress in this study refers to the difficult or challenging situations resulting from the country's negative economic state. Such situation could lead to an unmitigated disaster. From a psychological point of view, the disaster could be a shocking, stressful, and could lead to anxious change in an individual's life (Kapuvari, 2010). Physical and psychological stressors and likely reactions to anxiety could set the stage for worsening or even triggering almost any form of physical illness directly, not just those considered stress related. Most typically, though, anxiety could be seen as an on-going interactive process that could take place as individuals work towards adjusting to their environment both physically and psychologically.

Anxiety as a mood disorder could be characterised by warning signs of physical tension and uneasiness on possible future happenings. Not all anxious situations could be termed as bad. It could be good for an individual when it manifests in moderate amounts. Barlow and Durand (2012) observed that psychologists have on the other hand laid claim over a period time that people may perhaps do better when they are a somehow concerned or apprehensive. Barlow and Durand noted that physical and intellectual performances could be motivated and improved by anxious state of the individual. That perhaps could explain why some scholars referred to it as "future-oriented mood". Nevertheless, it is when one experiences considerable level of anxiety that it would be seen as posing a problem.

Many people today appear to have experienced different anxiety situations, which includes generalized anxiety disorder (GAD), phobic anxiety disorders, post-traumatic stress disorder (PTSD), panic disorder, among others. There are some common symptoms and the most of it according to Statens Helsetilsyn (2005) include light-headedness, heart palpitations, nervousness, trembling, tension, dizziness and stomach discomfort. Likely worries and apprehensions concerning things or circumstances surrounding the individual could also affect the mental wellbeing. 
Issues bordering on the mental health of students in Nigeria and other parts of the world are gradually becoming an area of increasing concern. Savarkar and Das (2019) in their study noted that there is a strong relationship between mental health and total holistic development of a person. Hence, good quality of life is many a time considered as the foundation of sound mental health. A study by Christensson, Vaez, Dickman, and Runeson (2011) indicated a high occurrence of anxiety and depression among the medical students of the university. Similarly, a research conducted by Haldorsen, Bak, Dissing, and Petersson (2013) measured stress levels and depressive symptoms among university medical students. The study revealed that practically, about one-third of the students that participated in the study reported feeling depressed. Similarly, a study conducted by Bayram and Bilgel (2008) among university students in Turkey indicated a disturbingly high incidence of anxiety, depression and stress symptoms. In a recent study conducted in China, Cao, et al., (2020) pointed out that there is a positive relationship between economic effects on daily life, delays in academic activities and development of anxiety symptoms.

Due to the negative shock arising from the Covid-19 economic shutdown, the issue of how to survive seems to have become of serious concern to many people. Anxiety due to fear for survival became usual mental response. Nigerian government seemed indifferent to the plight of the masses; hence the government's socioeconomic policy in response to the economic shutdown did not help matter as it rather increased public anxiety. As Tubadji et al., (2020), noted, the socioeconomic framework is a function of the way in which life is structured and the security network to which people rely on for their survival. Restrictions due the Covid-19 ended up shutting down almost every sector of the economy.

Although economies around the world seem to have gotten the hashness of COVID-19 lockdown, Nigerian youths and their families seem to have suffered the brunt of it as they have gone through many ordeals. Beside the huge army of employed youths roaming the streets, many who were initially engaged in works suddenly lost their jobs and became unemployed; while many were homeless and nearly starving of hunger. Support from the government was expected to come, but all expectations seemed not forthcoming. The little assistance received came mainly from a joint effort of NGOs and notable philanthropists in the form of emergency food items. The impacts of the shutdowns are numerous to families; it seemed even particularly more severe for young people, especially those in higher education. Some of the impacts will likely fade out over time, but others such as impacts arising from the living status and housing condition of many families may remain persistent if not properly addressed.

Living status and housing condition are notable economic factors that could create distress for many families and individuals in Nigeria. For a long time, the issue of housing condition has been recognized as one of the most critical concerns that influence the wellbeing of a person. Bonnefoy (2007) notes that living status and housing conditions are the foundations of numerous factors impacting on the total wellbeing of an individual. Home safety, indoor temperatures, noise, moisture, indoor air quality, mold growth, unpredictable organic compounds, a dearth of proper hygiene and sanitary equipment among others are a few of the foremost important conceivable wellbeing dangers that could be observed in many houses. Thus, one could assert from the foregoing that physical, mental and social wellbeing seem in this way could be influenced by the individual's living conditions, which in turn may lead to the persons concerned becoming anxious.

Furthermore, housing condition and the environment represent a commonplace view, which could support or hinder the mental, social and physical wellbeing of the housing dwellers. Consequently, living and housing conditions could be linked to or be classified as contributing factors influencing the health of individuals. Although, up till date, there seems no universally accepted description of what makes up a healthy or unhealthy housing and how it could contribute to both mental and physical wellbeing and disorders, especially in developing countries like Nigeria.

In Nigeria, disorders related to the issues of psychological health in young people surprisingly are becoming a common occurrence (ljarogbe, Okulate, Ladapo \& Law, 2011). In this economic 
shutdown era, however, even though WHO and a whole lot of others like Nigeria Centre for Disease Control (NCDC), scholars and health specialists are providing the needed guidance and responding to the public in attempt to clear their confusions and mitigate their fears, there is still growing anxiousness among the people. If urgent attention is not giving to address issues related to anxiety disorders, a large percentage of children and young adults may be grossly affected. Although in Anambra State, Nigeria, COVID-19 cases were very minimal, however, shutdowns and restriction imposed by both the State and Federal government, coupled with the strike action embarked by the Academic Staff Union of Universities (ASSU) have not helped matter, and the students seem to be receiving the brunt of the distressing situation sitting at home since the schools are all closed.

Schools have been suspended nationwide, such that almost $99 \%$ of enrolled learners at all levels of education in Anambra State are not only out of school, but are out of any formal education. For these students, not only are they confused and challenged mentally by the situation, but for those in need of counselling and therapy, the closure of the school could mean a total lack of access to the helpful resources they could have had while in school. The economic shutdown situation thus brought with it the danger of possible death from the infection and an unpleasant privations and emotional pressure for the students and the like. In such a dire situation, there is completely no access to mental health support and the usually available peer support groups have been put on hold.

Already, recent evidence across the globe (example, Brooks et al., 2020) suggests that persons that are held in isolation and those being placed on quarantine experiences substantial distress manifesting symptoms of anxiety, confusion, irritation, and post-traumatic stress symptoms. Nevertheless, the absence of empirical research in this area over the years in Nigeria means that it could be challenging when assessing the overall effect of the economic distress on the development of anxiety symptoms amongst young people, especially those in the university in Anambra State, Nigeria.
Previous studies such as Barlow and Durand (2012), Haldorsen, et al., (2013) and Cao, et al., (2020) have put forward an idea linking economic distress and major depressive and anxiety disorders. The causes of these disorders as Barlow and Durand noted could be traced to a complex interface of psychological, biological, and social/economic factors. The socioeconomic status factors include variables such as housing condition and living status, and the psychological factors refer to thoughts, feelings, and other psychological characteristics that affect the behaviour, attitude and functions of the human mind. These factors were examined in this study, titled, economic distress arising from COVID-19 economic shutdown as a factor in the development anxiety symptoms among students.

In consideration of these factors, it would be stimulating to examine whether economic distress arising from the COVID-19 economic shutdown as currently being experienced in the recessed economy in Nigeria increases the likelihood of students in the university developing anxiety symptoms. The Researchers are interested in finding out whether students who have financial difficulties which are likely to affect their housing condition and status of living are likely to experience anxiety symptoms, as they are likely to have less focus solely on their studies. Being that there is clear lack of empirical knowledge on how housing conditions and living status arising from a economic shutdown situation could contribute to the development of anxiety symptoms, especially among students in the universities in Anambra State, Nigeria. This is a gap in knowledge which this study intends to fill.

\section{Purpose of the Study}

This study examined economic distress arising from COVID-19 economic shutdown as a factor in the development of anxiety symptoms among undergraduate students in Anambra State, Nigeria. Specifically, the study examined:

- Distribution scores of the undergraduate students on housing condition.

- Distribution scores of the undergraduate students on living status.

- Distribution scores of undergraduate students 
on anxiety symptoms.

- Relationship between housing condition and anxiety symptoms experienced among undergraduate students in Anambra State.

- Relationship between living status and anxiety symptoms experienced among undergraduate students in Anambra State.

\section{Significance of the Study}

Findings of this study will beneficial to the students, guidance counsellors, classroom teachers and the society at large.

Specifically, the findings of the study will be beneficial to students. The Students are the ones more likely to face the challenge of these anxiety symptoms possibly due to economic distress; hence they stand to benefit so much from this study. This study will help students get more of the needed help from counsellors and other allied professionals having gained better knowledge of the tool towards reducing the tension and apprehension that could arise during pandemic and thereby being positioned to increasing students' wellness and performance in academic activities. This can be achieved through individual and group counselling.

Findings of this study will benefit teachers at all levels of education. The study will help early childhood teachers and those higher institutions to understand their pupils/students behaviours, especially in a period of distressing economic distress as currently being witnessed in Nigeria. They will be able to easily detect the anxiety prone pupils/students in order make proper referral of them to counsellors who are in position to assist and manage them with appropriate counselling techniques.

The findings of the study will equally expose teachers to understand anxiety symptoms better; so that proper referral can be made in directing students to counsellors. Exposing teachers about anxiety and the behavioural signs which they see in the classroom, makes this invisible disability called test anxiety easier to detect and understand.

The findings of this study will be beneficial to the counsellors and therapists. Guidance counsellors and therapists are in position to understand better the negative effect that excessive anxiety on students portends. So, the findings of this study will be of great assistance to them in getting the best out of every child. Findings from this study will provide the needed knowledge to render any helpful assistance to an anxious pupil or student.

\section{Research Questions}

The following research questions guided the study.

- What are the distribution scores of the undergraduate students on their housing condition in the university?

- What are the distribution scores of the undergraduate students on their living status in the university?

- What are the distribution scores of the undergraduate students on anxiety symptoms?

- What is the relationship between housing condition and anxiety symptoms of undergraduate students in Anambra State?

- What is the relationship between living status and the anxiety symptoms of undergraduate students in Anambra State?

\section{Method}

\section{Research Design}

The study was conducted using a correlational survey research design. A correlational survey design is considered appropriate for this study because it seeks to establish a relationship between two variables. The study was conducted in Anambra State, Nigeria.

\section{Study Area}

Anambra State is the area of study. Anambra State is located in the South East Geo-Political Zone of Nigeria. The state capital is Awka and its major commercial cities are Onitsha and Nnewi. The area is mostly known with trading, commerce and industries. The state is bounded in the east by Enugu State, in the west by Delta State, in the north by Kogi State, and the south by Abia and Imo State. The state government in response to the threat posed by the COVID-19 virus, all the schools and boundaries with neighbouring states were closed and all the 63 major markets in the State shut down to reduce the spread of the COVID-19 virus. These measures consequently led to total shut down of all economic activities in the State. 


\section{Participants}

The population of the study is 39,697 undergraduate students. This comprised of 26,229 undergraduate students from Nnamdi Azikiwe University, Awka and 13,468 undergraduate students from Anambra State University, Igbariam and Uli Campuses. Sample size for the study is 1,900 undergraduate students selected through a multi-stage sampling procedure.

\section{Instrument for Data Collection}

The instruments for data collection are questionnaires with two sections titled; "Economic Survey Questionnaire (ESQ)" and "Beck Anxiety Inventory (BAI)". The Economic Survey Questionnaire has two sections: $A$ and $B$. the questionnaires were adapted from Socioeconomic Survey Questionnaire modified to suit the purpose of the current study. The surveys were designed to cover issues regarding income and expenditures (Living status) and Housing and infrastructure (housing condition) of the students during the COVID-19 lockdown period. The housing condition is measured with 12 items, with response of Good $=4$, Fair $=3$, Poor $=2$ and Very Poor $=$ 1. The Beck Anxiety Inventory is a standardised instrument developed by Beck, Epstein, Brown and Steer (1988). The scale is a self-report measure of anxiety. It has 21 items with four response options measuring low, moderate and high anxiety scale. The instrument was validated by experts in measurement and evaluation. The reliability of the instrument was determined and a reliability coefficient alpha of 0.93 for PESQ and 0.92 for BAI was obtained.

\section{Data Collection and Analysis}

Data was collected by sending the questionnaires along with the consent form appended to it through e-mails, WhatsApp and telegram messengers to the contacts of the researchers. The participants were encouraged to forward to ten fellow students on their contacts. The questionnaire retrieval yielded a return rate of 73 percent. The retrieved questionnaire was then analysed using SPSS as follows: Percentages for the research Questions 1-3, Pearson product Moment Correlation Coefficient for the research questions 4 and 5.

\section{Results and Discussion}

In this section, the data collected from the field for this study were analyzed.

\section{Research Question 1}

What are the distribution scores of living status of undergraduate students in the university?

Table 1: Range of distribution scores on the living status of undergraduate students in the universities

\begin{tabular}{llll}
\hline Range of scores & N & $\%$ & Remarks \\
\hline $12-30$ & 253 & 18.2 & Fair living status \\
$31-48$ & 1134 & 81.8 & Poor living status \\
\hline
\end{tabular}

Table 1 reveals that $1134(81.8 \%)$ of the undergraduate students with the aggregate scores ranging from 31 to 48 rated their living status poor, while 253(18.2\%) others who scored between 12 and 30 rated their living status fair. The findings as revealed in the table indicates that majority of the students are living poorly.

Table 2: Range of distribution scores of undergraduate students' on their Housing condition in the university

\begin{tabular}{llll}
\hline Range of scores & N & $\%$ & Remarks \\
\hline $10-2$ & 919 & 66.3 & Poor Housing condition \\
$26-40$ & 468 & 33.7 & Fair housing condition \\
\hline
\end{tabular}




\section{Research Questions 2}

What are the distribution scores of undergraduate students on their Housing condition in the university?

Table 2 shows that $468(33.7 \%)$ of the undergraduate students with the scores ranging from 26 to 40 rated their housing condition Fair, while $919(66.3 \%)$ others who scored between 10 and 25 rated their housing condition Poor.

\section{Research Question 3}

What are the distribution scores of undergraduate students on anxiety symptoms?

Table 3: Range of distribution scores of the undergraduate students' anxiety symptoms

\begin{tabular}{llll}
\hline Range of scores & N & $\%$ & Remarks \\
\hline $21-52$ & 448 & 32.3 & Severe symptoms of anxiety \\
$53-84$ & 939 & 67.7 & Mild symptoms of anxiety \\
\hline
\end{tabular}

In table 3 , it was observed that $448(32.3 \%$ ) of the undergraduate students with the scores ranging from 21 to 52 indicated experiencing severe anxiety symptoms, while 939(67.7\%) students who scored between 53 and 84 indicated Mild symptoms of anxiety.

Table 4: Pearson $r$ of the undergraduate students' housing condition and their anxiety symptoms in universities in Anambra State

\begin{tabular}{lcccc}
\hline Source of Variation & $\mathbf{N}$ & Housing condition $\mathbf{r}$ & Anxiety symptoms $\mathbf{r}$ & Remark \\
\hline Housing condition & 1387 & 1.00 & 0.24 & Low Positve Relationship \\
Anxiety symptoms & 1387 & 0.24 & 1.00 & \\
\hline
\end{tabular}

\section{Research Question 4}

What is the relationship between housing condition and anxiety symptoms of undergraduate students in Anambra State?
Table 4 indicates that there is a low positive relationship of 0.24 existing between the housing condition of the university undergraduates and their anxiety symptoms.

Table 5: Pearson r on the undergraduate students' living status and their anxiety symptoms

\begin{tabular}{lcccc}
\hline Source of Variation & $\mathbf{N}$ & Living Status $\mathbf{r}$ & Anxiety Symptoms $\mathbf{r}$ & Remark \\
\hline Living Status & 1387 & 1.00 & 0.33 & Low Positve Relationship \\
Anxiety Symptoms & 1387 & 0.33 & 1.00 & \\
\hline
\end{tabular}

\section{Research Question 5}

What is the relationship between the living status and anxiety symptoms of undergraduate students in Anambra State?
Table 5 reveals that there is low positive relationship of 0.33 existing between the university undergraduate students living status and their anxiety symptoms. 


\section{Discussion}

Findings from the study reveal that majority of the undergraduate university students have poor living status, while only a few indicated fair living status. This shows that the current living status of the respondents in the universities under study was poor, which is an indication that most of their needs while in school are not being met. This suggests a possible distressing situation which could be explained thus; firstly, most of the students seem to be having challenging times in school due to the economic situation of the country that may have affected the family income. Secondly, the lockdown due to the COVID-19 economic shutdown seem to have fuelled the distressing economic situation as most of the businesses were adversely affected, hence the likelihood of lowering the family income. The result is thus in support of the finding of the previous study such as Vera-Toscano and AcetaAmestoy (2008) whose study indicated that people from the lower-income families may not be able to afford some things needed to attain good living status, hence, they are less likely to be happy with their living status. Secondly, the larger population of participants in the study are mostly students in their youths; this may have also been responsible for the observed poor rating in the study. The finding seems to be in agreement with the Lu (2002) report that younger people are not as much likely to be contented with their living status.

More so, findings from the study further revealed that there is a low positive relationship existing between the university undergraduate students living status and their anxiety symptoms. What this implies is that there is the likelihood that the undergraduate students living status could predict their anxiety symptoms in the university. This finding is in line with Bayram and Bilgel's (2008) whose study was conducted among groups of university students in Turkey, revealed that anxiety and stress were higher among students with low standard of living. Bayram and Bilgel's study further noted that the students who received more financial support from their parents were found to have lower levels of anxiety, stress and depression than the students who received a lesser amount of or no support financial support.

Thus, from the foregoing, one can accept the notion that there is a likely connection between financial resources possibly provided by parents or caregivers and the ales likelihood of the students developing anxiety symptoms. Similarly, one could also assume that the students living merely on the little they could get from parents, relations, and personal effort would require an ample amount of time in managing their studies as many of the students in some instances have to engage in doing hard odd jobs in addition to full-time studies in order to perform well academically. Also, these students sometimes may have to deal with mounting pressures from both the school and their respective place of work. In such situation, they would likely have themselves exposed to more anxiety situations.

Findings further reveal that majority of the students indicated having poor housing conditions, while few of the students indicated having a fair housing condition. The students' responses on the questionnaire used in assessing the housing condition, their responses revealed the key dimensions of housing conditions and the students also responded to explain the state of their housing situation and satisfaction with the residential facilities. The outcome of the study is an indication that the distressing economic situation may have played a role being that the majority rated their housing condition poor. This finding is in line with Bonnefoy (2007) whose study examined the influence of housing conditions on the well-being of occupants observed that the evidence base for the complex effects of housing conditions on health is growing.

The findings of the study showed that majority of the respondents in all the universities under study felt that their present living status falls below their expectation and possibly unable to meet their needs. A number of reasons can be given to clarify this outcome; in the first instance, a dominant part of the respondents in the study were from low-income families, this seems to creates the impression that the outcome is on the side of the finding of the past study, for example, Vera-Toscano and Aceta-Amestoy (2008). The study demonstrated that may not be able to afford good and comfortable living and are less likely to be happy with their economic conditions. Furthermore, the respondents in the example who are mostly youths may have additionally represented the observed poor rating in the current study, which is in some accounts consistent with Lu (2002) whose 
study uncovered that more youthful individuals are more averse to be happy with their states of living.

Moreover, the undergraduate students' scores on anxiety symptoms indicated that the majority experienced mild anxiety symptoms while some others experienced severe anxiety symptoms. The finding show that the students manifest somatic symptoms, like fretting, tensions, heart palpitations, pain, heavy and rapid breathing, dizziness, fainting, indigestion, stomach aches, and in some extreme cases diarrhoea. This finding is troubling as the lives of those students experiencing severe form of anxiety could grow into or become totally controlled by the anxiety situation. This means they may not find it easy to relax or have steady pattern of good sleep. They may become trapped in a pattern of thought that could weaken their capacity to sustain ones chosen way of life, being able to concentrate in their studies or sustain personal relationships.

These finding is also in agreement with Stossel (2014) whose survey research showed that majority of persons that participated in the study feel anxious either a lot of the time or all of the time. The finding is concerned with the way people experience different types of anxiety, and how they are represented in the study population. The study also explored the commonplace indicators in addition to what could happen when anxious situation turn out to be more than a momentary experience and rather is experienced as a constant presence in an individual's life or a series of debilitating episodes.

The finding moreover indicates that there is a low positive relationship existing between the housing condition of the university undergraduates and their experience of anxiety symptoms. What this means is that poor housing conditions could contribute slightly to the possibility of a student developing anxiety symptoms. The findings show that anxiety symptoms such as fear of the worst happening, inability to relax or fear of losing control among others may be triggered by the individual being close to specific circumstances or a persistent uneasiness that something rather unpleasant may happen in the future. This finding is in agreement with Bonnefoy (2007) who observed that poor quality of the house, insufficient protection from scrutiny, from noise, from the outside and disturbances could be major source of worry and anxiety. Situations like that as Bonnefoy stated could generate compulsive manifestations of social dysfunction, paranoid feelings, insomnia and anxiousness.

\section{The Implication of the Study}

Findings from the study offer certain practical implications.

The findings of the study have important implications for the students. This is because the financial pressure experienced by the students as a result of the distressing economic situation may possibly escalate the risk of mental health issues, especially among undergraduate students. This creates the need for government and other concerned citizens to ensure that there are enough resources and that organizations offering practical assistance and support are available to assist the students.

Another important implication of the study is that since the findings of the study have exposed one to the possible predictors of anxiety symptoms among the undergraduate students and the need for the guidance counsellors in the school to help to explore varieties of ways of coping with the feelings of anxiety and dealing those predictors of anxiety.

The study findings reveal that mental health service provision needs to remain a priority, especially for high-risk groups such as undergraduate students who are likely to be under financial pressure and are at risk of developing anxiety symptoms.

\section{Conclusions}

The findings of this study reveal that there is a positive relationship between living status, housing condition, and anxiety symptoms experienced by the undergraduate students in the universities. This study thus provided an important understanding on the possible relationship between economic situation of a person and development of anxiety symptoms. The study, therefore, highlights those areas of student's lives most likely to generate feelings of anxiety; living status and housing conditions were linked to possible cause of anxiety, while financial issues feature prominently in the students' concerns. 


\section{Recommendations}

Based on the findings of this study, it is recommended that:

- Government and other concerned citizens should ensure that low-cost housing and financial assistance in the form of allowances are made available to assist the students experiencing distressing economic situations in order to prevent the students from developing anxiety symptoms that are not healthy for them.

- There is a serious need to have fully functional guidance counsellors in the university who are not combining counselling with lecturing. These guidance counsellors in the school will help to explore a variety of ways of coping with the feelings of anxiety and possibly handling those predictors of anxiety before it becomes a serious problem for the students.

- The university community could initiate palliative measures such as reduced hostel fees, provision of feeding allowance to help students deal with the difficult economic situation as currently being experienced in the country.

\section{Funding}

None:The authors acknowledge that no funding was received for the entire work.

\section{Conflict of Interest}

The authors do not have any conflict of interest.

\section{References}

1. Barlow, D.H., \& Durand, M.V. (2012). Abnormal Psychology: An integrative Approach. (International Edition). Wadsworth, Cangage Learning.

2. Bayram, N., \& Bilgel, N. (2008). The prevalence and socio-demographic correlations of depression, anxiety and stress among a group of university students. Social Psychiatry and Psychiatric Epidemiology, 43, 667-672.

3. Beck, A.T., Epstein, N., Brown, G., \& Steer, R.A. (1988). An inventory for measuring clinical anxiety: Psychometric properties. Journal of Consulting and Clinical Psychology, 56, 893897.

4. Bhardwaj, R.L. (2001). Manual for Socioeconomic status scale. Agra: National Psychological Corporation.

5. Bonnefoy, X. (2007). Inadequate housing and health: an overview. International Journal of Environment and Pollution, 30(3), 411-429.

6. Brooks S.K., Webster R.K., Smith L.E., Woodland L., Wessely S., Greenberg N., Rubin G.J. (2020). The psychological impact of quarantine and how to reduce it: Papid review of the evidence. Lancet. Retrieved from https:// scholar.google.com/

7. Cao, W., Fang, Z., Hou, G., Han, M., Xu, X., Dong, J. \& Zheng, J. (2020). The psychological impact of the COVID-19 epidemic on college students in China. Psychiatry Research, 287, 112934. DOI: 10.1016/j.psychres.2020.112934.
Retrieved from https://europepmc.org/article/ $\mathrm{med} / 32229390$.

8. Christensson, A., Vaez, M., Dickman, P.W., \& Runeson, B. (2011). Self-reported depression in first-year nursing students in relation to socio-demographic and educational factors: a nationwide cross-sectional study in Sweden. Social Psychiatry and Psychiatric Epidemiology, 46, 299-310.

9. Haldorsen, H., Bak, N.H., Dissing, A., \& Petersson, B. (2013). Stress and symptoms of depression among medical students at the University of Copenhagen. Scandinavian Journal of Public Health, 42, 89-95

10. Ijarogbe, T.G., Okulate, G.T., Ladapo, H.T.O., \& Lawal, R.A. (2011). Prevalence of anxiety and depressive disorders among informal caregivers of patients attending the Federal Neuropsychiatric Hospital, Yaba, Lagos. Nigerian Journal of Psychiatry, 19(2), 14-29.

11. Kapuvari, V. (2010). Psychological effects of economic recession and unemployment. European Journal of Mental Health 6(2011), 83-93. DOI: 10.5708/EJMH.6.2011.1.4

12. Lu, M. (2002). Are pastures Greener? Residential consequences of migration. International Journal of Population Geography, 8, 201-216.

13. National Bureau of Statistics (NBS, 2020). Nigeria's Gross Domestic Product. Retrieved from www.nigerianstat.gov.ng

14. Rogne, S.F. (2015). Effects of economic 
situation and gender on anxiety and depression in full-time psychology students. Avdelningen för socialt arbete och psykologi, Handledare: Igor Knez

15. Savarkar, T. \& Das, S. (2019). Mental health problems among street children: The case of India. Current Research Journal of Social Sciences, 02(1), 39-46. Retrieved from http:// journalofsocialsciences.org/pdf/vol2no1/ CRJSSH_Vol02_No1_p_39-46.pdf

16. Statens Helsetilsyn. (2005). ICD-10 Psykiske Lidelser og Atferdsforstyrrelser - Kliniske Beskrivelser og Diagnostiske Retningslinjer. Oslo: Gyldendal.

17. Stossell, S. (2014). Living with anxiety:
Understanding the role and impact of anxiety in our lives. Mental health foundation.

18. Vera-Toscano, E., \& Ateca-Amestoy, V. (2008). The relevance of social interactions on housing satisfaction. Social Indicators Research, 86, $257 \mathrm{e} 274$.

19. World Health Organisation (WHO, 2020). Coronavirus. Retrieved from https://www.who. int/health-topics/coronavirus

20. World Health Organisation (WHO, 2020). WHO urges countries not to let COVID-19 eclipse other health issues. Retrieved from http:// whotogo-whoafroccmaster.- newsweaver com/ JournalEnglishNewsletter/ 